\title{
Applied Psychology. The Case of the Baer, Wolf and Risley Prescriptions for Applied Behavior Analysis
}

Psicologia aplicada. El caso de las prescripciones de Baer, Wolf y Riesley para el análisis aplicado de la conducta

Recibido: diciembre 13 de 2013 | Revisado: febrero 16 de 2014 | Aceptado: julio 17 de 2014

\author{
Heliodoro Carpintero Capell * \\ Universidad Complutense de Madrid \\ VICTORIA DEL BARRIO, \\ UNED, Madrid \\ RiCHARD MABABU \\ UDIMA, Madrid
}

doi.org/10.11144/Javeriana.upsy13-5.aptc

Para citar este artículo: Carpintero Capell, H., Del Barrio, V., \& Mababu, R. (2014). Applied psychology. The case of the Baer, Wolf and Risley prescriptions for applied behavior analysis. Universitas Psychologica, 13(5), 1721-1728. http://dx.doi. org/10.11144/Javeriana.upsy13-5.aptc

E-mail: carpinte@filos.ucm.es

\author{
A B S T R A C T \\ Baer, Wolf and Risley, members of the group that promoted the creation of \\ the Journal of Applied Behavior Analysis, offered in its first issue a detailed \\ series of 'prescriptions' that characterized the way research and research \\ articles would be conceived as adequate to the applied field by the journal \\ editors. Their 'prescriptions' have been largely cited, becoming a sign of \\ authors' identification with the journal policy, and widely influencing the \\ structure and topics of this specialized literature. \\ Keywords \\ applied behavior analysis; prescriptions; Journal of Applied Behavior Analysis

\section{RESUMEN} \\ El "Journal of Applied of Behavior Analysis" publicó en su primer número, \\ en 1967, unas reglas o prescripciones, elaboradas por tres miembros del \\ grupo editorial (Baer, Wolf y Riesley), que han servido eficazmente para \\ orientar a los futuros autores acerca del modo como construir los articulos \\ que podrían ser publicados en la revista. Esas prescripciones reunen las \\ principales características propias de la investigación aplicada en el campo \\ del análisis conductual. \\ Palabras clave \\ análisis aplicado de la conducta; prescripciones; Journal of Applied Behavior \\ Analysis
}


One of the strongest and wide currents in the field of contemporary applied psychology is that of the applied behavior analysis. This movement was born in the second half of the 20th century, inside the field of the experimental analysis of behavior. Based upon the theoretical findings of B.F. Skinner on operant conditioning, it turned soon into a powerful area of theoretical research, mainly dealing with learning topics.

A special journal, the JEAB (Journal of Experimental Analysis of Behavior) was created in the United States, in 1957, to publish the growing number of papers produced by many research groups working in the area.

In 1967, the increasing development of an applied orientation inside the new field made necessary the creation of another journal, which would take care of this production. Following a suggestion by Nathan Azrin (Kazdin, 1978, p. 276), it was founded the Journal of Applied Behavior Analysis (JABA), under the editorship of a group of researchers gathered around a new doctoral program on that topic at the University of Kansas, USA. It soon became a powerful research front group inside the field. It was formed by researchers coming from the field of the JEAB, together with others from the tradition of Sidney Bijou and Donald Baer, who had created an active working group on operant conditioning at the University of Washington (Krantz, 1973).

The need for a journal fully oriented to intervention and applied topics was mostly due to the strong disparity of criteria that had risen between the supporters of the theoretical analysis and those dealing with practical intervention in social problems. Questions under debate were different; in the later group there was also a growing demand for social useful answers, and findings were valued according to their practical applicability. The new field offered "a continuous progression from basic research (i.e., experimental analysis of behavior) to applied research" (Schorr, 1987, p. 38). All these factors created a growing gap between both groups that, although maintaining different orientations, never cut their 'each other' relationship.
In 1967, in the first issue of the JABA journal, it appeared an article that turned out to be one "extremely influential paper"; it was "seen as a position paper that defined the realm of study for the journal" (Kazdin, 1978, p. 276). Its title was "Some current dimensions of applied behavior analysis". Donald Baer, Montrose M. Wolf, and Todd Risley signed it. All the three were narrowly intertwined among them, and they belonged to the editing group of the publication. All of them were working on the application of the new concepts of operant conditioning to various types of practical problems.

\section{The authors}

The three mentioned authors, Baer, Wolf, and Risley, attracted by the possibilities for social applications of the behavior analysis technology, had joined the University of Kansas, then promoting such kind of research.

Donald Baer (1931-2002) had devoted himself very soon to the study of child development from a neobehaviorist perspective, in the University of Washington. There he narrowly collaborated with Sidney W. Bijou. Later, he moved to the University of Kansas, where he did an important work on the problems of reinforcement and its effects on the extinction of certain infantile disruptive conducts.

He invited Montrose M. Wolf and Todd R. Risley to join his group at Kansas, where they organized a research team on applied behavior analysis (ABA). Research was centered on behavioral problems, either of individual or of sociocultural importance, and their studies, largely related to child behavior, soon became very influential in the field.

Todd R. Risley (1937-2007) was also a worldrenowned pioneer in applied behavioral studies. In the University of Kansas, he worked at the Department of Applied Behavioral Science and at the Schiefelbusch Institute for Life Span Studies. Many years later, he moved to the University of Alaska. His studies on how children acquire language, and on child behavior in various community settings are widely known. 
Montrose M. Wolf (1935-2004), after his initiation at the University of Washington, joined Baer's group at the University of Kansas, and did important research on reinforcing power of adult attention for children. In doing so, he put the basis of what has been considered as a nonviolent parenting procedure. He also explored other aspects of a comprehensive teaching-family model, and of the problem-solving behavior in real-world settings.

All of them assumed an experimental approach to the study of significant human behavior out of the laboratory, in real world settings, helping people to adapt themselves to the world.

\section{The article.}

In his well-known History of behavior modification (1978), Alan Kazdin indicates that the cited article by Baer, Wolf, and Risley intended to define the field of applied analysis, depending on both methodological and content criteria. They wanted to clarify and orient other people on how to prepare their contributions for the new journal, in a way that could help them prepare their papers in a successful way to get them published. In so doing, they tried to delimit, at least from their own perspective the applied field, according to the principles of the experimental analysis of behavior.

The declaration was an important and useful one, as its authors became the first editors of the journal, and their adopted criteria served as demarcation lines for the specialized field that the magazine intended to cover. It is easy to understand that those authors aspiring to publish in the journal would explicitly assume such criteria. Accordingly, the article was cited time after time, and it became one of the most cited pieces in contemporary clinical psychology. In fact, between 1968 and 1982, the article had been cited 535 times (with a mean of 38'21 times a year). The Current Contents magazine, in its section of 'contemporary classics' dedicated to highly visible works, included a mention to the article with a short comment by its first author, Donald Baer, in 1982. On such grounds, it was considered as a paper with great impact upon the scientific psychological literature, (Smelser,
1987). It may be also noted that, according to Google scholar (November, 2013), it would have been cited 2540 times in 45 years, since its appearance, (56'44 times yearly): an impressive visibility for the time considered.

Baer has referred, in his comment (Baer, 1987), how was the context in which they wrote it. As it has been already said, it was the fruit of an investigative Project, born at the University of Kansas, USA, in 1966, strongly inspired by the principles of the operating conditioning theory, and orientated towards the study of relevant social problems.

As Baer says, the working group wanted to prove that the methodology based on the experimental analysis of behavior was relevant for solving social problems. Its procedure was not a simple one. "These applications would not be automatic, obvious, or simple; they would require a great deal of integrated step-by-step research that would vary from the laboratory methods in which most of us had been socialized" (Baer, 1987, p. 108).

For these journal editors, the core problem was to clarify how the new field of applied behavior analysis should be build, as a true scientific field. The article sought to provide researchers with "a description of how the necessary data might be gathered, and what a field gathering that kind of data could be like" (Baer, 1987, p. 108).

They looked at the requirements and conditions of a true scientific approach to practical problems of life. In their article they offered a sort of guidelines or prescriptions for all the possible contributors that wanted to work in such practical field. In so doing, they helped to clarify the possible limits that could serve to define the applied field in psychology.

\section{The required characteristics}

In this approach to applied methodology, it is emphasized that both the experimental and the applied behavior analysis have some traits in common. Both methods are oriented to the discovery of those mechanisms controlling certain specific behaviors; both also employ the analysis of variables, and apply a simultaneous evaluative process to establish whether or not the intervention process 
has caused any attributable effect. Any possible change in terms of mere developmental grounds would here be excluded.

In short, the analytic procedure should be considered as "a self examining, self-evaluating, discoveryoriented research procedure for studying behavior" (Baer et al., 1968, p. 91). In this view, the differentiation between applied and non-applied (theoretical) research programs would not be based in the opposition of 'discovery' versus 'application'. As a matter of fact, both lines had to determine the relevant behavioral variables, their functional interrelation, and the causal interactions between them determining their increase or decrease of the studied behavior -in case, its consolidation or inhibition. But such commonalities could not conceal the profound dissimilarities between both procedures. As Baer et al. maintained, analysis applied to a practical problem would be somewhat different from another one employed in examining a problem in a laboratory setting. These differential characteristics might be taken as being typical traits of any applied intervention in psychology. They have been described as follows:

"Obviously, the [applied] study must be applied, behavioral and analytic; in addition, it should be technological, conceptually systematic, and effective, and it should display some generality" (Baer et al., 1968, p. 92).

Let us consider them more closely.

\section{The differential traits}

\section{a) Behavioral.}

Let us begin with the trait of the behavioral character that the study necessarily must have. When an individual is put under study and treatment, "the relevant question is not what he can say, but what he can do". Behavior is always "composed of physical events" (Baer et al., 1968, p. 93), or, as it was aptly stressed by M. Yela, of physical and meaningful movements (Yela, 1987); in other words, it is a synthesis of physical and ideal dimensions forming a whole.

The physical dimension of behavior implies a need for it to be measured, as other physical entities when put under scientific scrutiny. This requires determining which behavior, and in what degree it has changed under the devised intervention. In many cases, such measurement will not be the result of a technical apparatus - the outstanding procedure -, but obtained from the appreciation of an observer, the only means to be used in many real life situations.

In any case, only some superficial differences can be viewed here to exist between an applied and a non-applied research on an individual behavior.

\section{b) Analytic.}

In the study of natural phenomena, analysis is the procedure that permits to break a phenomenon or a problem into its various constituents. Baer et al. (1968) consider 'analytic' a study in which the determining variables of a certain behavior are fixed and under the experimenter's control. "An experimenter has achieved an analysis of a behavior when he can exercise control over it" (Baer et al., 1968, p. 94). It is clear that, when it is taken for granted that a concrete behavior is a process to be described in terms of stimulus and response, as it is here the case, a well analyzed behavior will be that one in which both the response and the stimulus variable are known, and their relationship is also established, a cause-effect relation that brings about an effective control.

Analysis implies here the knowledge of the functional structure that is producing a certain behavior. But the correctness of such knowledge is proved only by the effectiveness of the control that the independent variable is showing to have upon the dependent one. Such a proof is mainly obtained through the application of an operative design, the ABAB design, which makes clear the correlation between both types of variables. The presence, in a greater or lesser degree of the independent variable is followed by the correlative appearance (in a greater or lesser amount) of the dependent one. The problem is that in many real settings, such a manipulation of variables is not easy to be done. And, in the end, "the problem... will be to make such an analysis reliable... (through) the repeated 
alternate use of different values on the same behavior" (Baer et al., 1968, p. 95).

According to this view, analysis means the determination of the S-R functional structure of a certain behavior, which both explains and controls it.

\section{Other traits}

Another examined trait is what is called here its 'technological' character. It implies the existence of a complete degree of description and of identification of the techniques employed by the experimenters in their work. A good applied procedure will be that one that provides us with a technique that enables anyone to replicate it by merely reading its description and carrying it into practice.

'Conceptual system' is another one. It refers to the need of being precise not only in the technological description, but also in connecting the proposed operation with those concepts and principles that are supposed to explain the devised intervention.

It can be thought that, until now, such traits make no difference while appearing related to an applied procedure or to a theoretical oriented one.

The case is not longer the same when other traits are examined.- 'Effectiveness' is one of them (Baer et al., 1968, p. 96). When might be considered an intervention to have been 'effective'? According to the authors, the criteria is not the same both in applied and in non-applied research. In the later, it is generally estimated that the desired goal has been reached when it is possible to show that a certain effect has been caused. By the contrary, the operation is usually conceived as worthless when only some minor effects are obtained. In the applied sphere, the "power in altering behavior enough to be socially important, is the essential criterion" (Baer et al., 1968, p. 96). For instance, when only small changes are obtained in an undesired problematic behavior under a certain treatment, the intervention under evaluation seems totally unjustified. Practical value of a method depends on its utility for obtaining a certain level of gains.

Moreover, when some good results are proved to be durable over time and the intervention shows a certain degree of generalization, affecting a varie- ty of related behaviors, then it can be said that this procedure has an acceptable degree of 'generality'. It would indicate that a consistent change has taken place in individuals, and that such change goes on the desired direction.

Magnitude, duration and generalization might be considered as mere aspects of what now we usually call the 'effect size' of the intervention, that is a measure of its strength and it is appreciated in evaluative meta-analysis of different treatments by clinicians.

According to all these factors, an applied technology or procedure should have a real practical value depending neither on the technical disposition of its elements nor in the simplicity of its methods, but on "the interest which society shows in the problems being studied" and solved (Baer et al., 1968, p. 92).

\section{The practical value}

In the end, practical interventions upon behavior would be evaluated according to the practical value system that operates in the daily life events of a certain society. Living estimates would then decide of the technological practice. As it is clearly stated here, "in behavioral application, the behavior, stimuli, and /or organism under study are chosen because of their importance to man and society, rather than their importance to theory" (Baer et al., 1968, p. 92).

It is worth to be noted that, although theoretical and applied analyses are employing different criteria in their respective evaluations, they do not look for different structures and elements when dealing with behavior. Both are accepting the supposition that behavior is an S-R living process, produced by an organism that fights to survive in a certain setting or environment. From the point of view of the 'what' that is dealt with in both cases, we are studying causal processes in which certain stimuli are determining certain responses, and all of them can be characterized by their adaptative value for the living subject.

But from the point of view of their practical utility, a certain proportion has to exist between 
the complexity of the action, and the worthiness of its obtained effect. While in the non-applied field results of a research are evaluated according to its impact on a theoretical body, in the applied field, by the contrary, they are measured by their impact upon human life as it is experienced in a certain society at a given time. In the former case, it is a matter of logical coherence, while in the later it is a matter of historical and social worthiness.

Other peculiarities have also to be mentioned. On the one hand, theoretical experimental researchers in psychology have been employing time after time laboratory animals in their studies for proving laws and theories; neobehaviorist E. C. Tolman, as it is well-known, dedicated his masterpiece Purposive behavior in animals and men (1932) to the 'Mus norvegicus', the White rat, that had been an essential piece in the building of that theory. By the contrary, when facing a practical problem, researchers usually deal with human subjects, and most of the times, with people immediately affected by it. Samples analyzed are obtained from the affected population, always trying to minimize the distance between them, as a mean to enforce the result validity. In so doing, researchers usually try to answer a basic question: "how immediately important is this behavior or these stimuli to this subject?" (Id., 93).

\section{Other differences}

Applied and non-applied (theoretical) research in the field of the behavior analysis also presents minor differences in methodological dimensions. Both are focused upon behavior and its S-R elements; both try to discover those functional relations that may explain behavior characteristics and changes; both take into consideration intrasubject changes that are to be related to environmental variations whose determining influence is evaluated; both are oriented toward observation and quantitative measurement of behavior, and several research designs are in common to both lines of work, although some of them have to be adapted to the requirements of the circumstances in which intervention is applied.

It is true that the technological complexity and the strict control that is normal at the laboratory research are usually not possible in applied research. Normal life taking place in social settings is not apt to be treated in the rigorous way that is usually employed in the laboratory. By the contrary, the use of independent observers for measuring target behavior is perhaps more common in applied than in non-applied research.

\section{A final remark}

The field of operant psychology, when considered from the point of view of the research carried out in it, shows a profound homogeneity and unity, apart from the duality of applied versus non-applied operations, and their respective goals and purposes. Apart from the differences above mentioned, the unity of its object of study, i.e., behavior, brings to it a profound coherence and compactness.

The experimental analysis of behavior is centered on the study of behavior structure and its determinants; in a coincident way, applied research also considers a certain type of behavior, i.e., applied behavior, whose own determinants tried to clarify. It must be noted that, since the early beginning of the behavioristic school, it was stressed by its founder, J. B. Watson, that behaviorism was looking not only for knowledge but also for control of the behavior. This implied the strict unity of both the applied and the experimental fields. In his own words:

"The desire in all such work is to gain an accurate knowledge of adjustments and the stimuli calling them forth. The reason for this is to learn general and particular methods by which behavior may be controlled. The goal is not 'the description and explanation of states of consciousness as such' ... If psychology would follow the plan suggested, the educator, the physician, the jurist, and the business man could utilize the data in a practical way, as soon as it could be experimentally obtained" (Watson, 1914, p. 11).

In making behavior its sole object of study, the particularities of the two approaches, the experimental and the applied one, vanishes, and it appears at a new light the profound unity of psychology as the science of behavior, that looks not only for explanation, and prediction, but also for the control of phenomena. 


\section{The significance of the article}

Baer, Wolf, and Riesley, in their article, clearly presented a descriptive view of applied psychology, as seen from the behavioral field, that served as a set of prescriptions for all those that tried to give public status to their own scientific contributions, through the JABA channel, widely accepted by that part of scientific community deeply influenced by the behaviorist model of psychology.

Their view had been so well specified and built that, nearly twenty years later, these authors did find the same traits as guiding the current behavioral literature, after all. Their comments were offered in a new article under a significant title: "Some still-current dimensions of Applied Behavior Analysis" (Baer, Wolf, \& Riesley, 1987). In its pages it is suggested that the paper largely contributed to give stability to idyosincratic literature, characteristic of the field.

"Twenty years ago, an anthropological note described the current dimensions of applied behavior analysis as it was prescribed and practiced in 1968: It was, or ought to become, applied, behavioral, analytic, technological, conceptual, effective, and capable of appropriately generalized outcomes. A similar anthropological note today finds the same dimensions still prescriptive, and to an increasing extent, descriptive" (Baer et al., 1987).

The early prescriptions, widely followed by contributors deeply interested in having their papers accepted in JABA, became assumed as the normal way of doing research in the field, and were not considered as external guidelines, but as some logical conditions orienting the experimental work.

Moreover, the prescriptive role played by the paper after its publication added to it a complementary semantic value, as a mark of theoretical identity for those other papers citing it and being accepted by JABA editors. As Baer says, the paper was cited "as a way of joining the field and identifying data as a contribution to it" (Baer, 1987, p. 108).

The authors also attributed another important function to their old article, that of becoming a reliable index to classify the theoretical orientation of current literature through citations. Such a function, largely acknowledged in bibliometric studies of scientific literature, is a sort of eponimic role, which permits to identify a topic through the pioneers names of the field. And such an effect was obtained through the citation of this paper that became used as a mark of belonging to this applied behavioral field.

It is then clear that, when trying to evaluate the article, we are facing a complex situation. On the one hand, it may be said that this article has had a prescriptive value for the literature in applied analysis of behavior, offering some guidelines for research and publication in the field. But, on the other hand, it has also had served as an index, or a clue to identify documentation related to that specialty, and this implies a relevance in the area of the scientific documentation and in the broader field of the history of contemporary psychology. Perhaps such multiplicity of roles attributed to the paper gives us the clue for its continuous presence among the highly cited psychological literature, for nearly half a century.

\section{References}

Baer, D. (1987). This week's citation classics: Baer, D. M., Wolf, M., \& Risley, T. In N. J. Smelser (Comp.), Contemporary classics in the social and behavioral sciences. Philadelphia, PA: ISI Press.

Baer, D., Wolf, M., \& Risley, T. (1968). Some current dimensions of applied behavior analysis. Journal of Applied Behavior Analysis, 1(1), 91-97.

Baer, D., Wolf, M., \& Risley, T. (1987). Some stillcurrent dimensions of applied behavior analysis. Journal of Applied Behavior Analysis, 20(4), 313-327. doi: 10.1901/jaba.1987.20-313

Kazdin, A. (1978). History of behavior modification. Baltimore: University Park Press.

Krantz, D. (1973). Schools and systems: The mutual isolation of operant and non- operant psychology as a case study. In M. Henle et al. (Eds.), Historical conceptions of psychology (pp. 116-128). New York: Springer.

Schorr, A. (1987). Behavior modification. In H. J. Eysenck \& I. Martin (Eds.), Theoretical foundations 
of behavior therapy (pp. 37-56). New York: Plenum Press.

Smelser, N. J. (Comp.). (1987). Contemporary classics in the social and behavioral sciences. Philadelphia, PA: ISI Press.
Watson, J. B. (1914). Behavior. An introduction to comparative psychology. New York: Holt.

Yela, M. (1987). Toward a unified psychological science. The meaning of behavior. In A. Staats \& L. P. Mos (Eds.), Annals of theoretical psychology (Vol. 5, pp. 241-274). New York: Plenum Press. 